\title{
Dietary Patterns during Lactation and Developmental Milestones, including Neurocognitive Development, in the Child: A Systematic Review
}

2020 Dietary Guidelines Advisory Committee, Pregnancy and Lactation Subcommittee

Published date: July 15, 2020

Nutrition Evidence Systematic Review Center for Nutrition Policy and Promotion

Food and Nutrition Service

U.S. Department of Agriculture

Braddock Metro Center II

1320 Braddock Place

Alexandria, Virginia 22314 
This systematic review was conducted by the 2020 Dietary Guidelines Advisory Committee in collaboration with the Nutrition Evidence Systematic Review (NESR) team at the Center for Nutrition Policy and Promotion, Food and Nutrition Service, U.S. Department of Agriculture (USDA). All systematic reviews from the 2020 Advisory Committee Project are available on the NESR website: https://nesr.usda.gov/2020-dietaryguidelines-advisory-committee-systematic-reviews.

Conclusion statements drawn as part of this systematic review describe the state of science related to the specific question examined. Conclusion statements do not draw implications, and should not be interpreted as dietary guidance. This portfolio provides the complete documentation for this systematic review. A summary of this review is included in the 2020 Advisory Committee's Scientific Report available at www.DietaryGuidelines.gov.

The contents of this document may be used and reprinted without permission. Endorsements by NESR, the Center for Nutrition Policy and Promotion, the Food and Nutrition Service, or the USDA of derivative products developed from this work may not be stated or implied.

Suggested citation for this systematic review: 2020 Dietary Guidelines Advisory Committee and Nutrition Evidence Systematic Review Team. Dietary Patterns during Lactation and Developmental Milestones, including Neurocognitive Development, in the Child: A Systematic Review. 2020 Dietary Guidelines Advisory Committee Project. Alexandria, VA: U.S. Department of Agriculture, Food and Nutrition Service, Center for Nutrition Policy and Promotion, July 2020. Available at: https://nesr.usda.gov/2020-dietary-guidelinesadvisory-committee-systematic-reviews.

Related citation: Dietary Guidelines Advisory Committee. 2020. Scientific Report of the 2020 Dietary Guidelines Advisory Committee: Advisory Report to the Secretary of Agriculture and the Secretary of Health and Human Services. U.S. Department of Agriculture, Agricultural Research Service, Washington, DC.

In accordance with Federal civil rights law and USDA civil rights regulations and policies, the USDA, its Agencies, offices, and employees, and institutions participating in or administering USDA programs are prohibited from discriminating based on race, color, national origin, religion, sex, gender identity (including gender expression), sexual orientation, disability, age, marital status, family/parental status, income derived from a public assistance program, political beliefs, or reprisal or retaliation for prior civil rights activity, in any program or activity conducted or funded by USDA (not all bases apply to all programs). Remedies and complaint filing deadlines vary by program or incident.

Persons with disabilities who require alternative means of communication for program information (e.g., Braille, large print, audiotape, American Sign Language, etc.) should contact the responsible Agency or USDA's TARGET Center at (202) 720-2600 (voice and TTY) or contact USDA through the Federal Relay Service at (800) 877-8339. Additionally, program information may be made available in languages other than English.

To file a program discrimination complaint, complete the USDA Program Discrimination Complaint Form, AD3027, found online at How to File a Program Discrimination Complaint and at any USDA office or write a letter addressed to USDA and provide in the letter all of the information requested in the form. To request a copy of the complaint form, call (866) 632-9992. Submit your completed form or letter to USDA by: (1) mail: U.S. Department of Agriculture, Office of the Assistant Secretary for Civil Rights, 1400 Independence Avenue, SW, Washington, D.C. 20250-9410; (2) fax: (202) 690-7442; or (3) email: program.intake@usda.gov.

USDA is an equal opportunity provider, employer, and lender. 
Pregnancy and Lactation Subcommittee:

- Sharon Donovan, PhD, RD, University of Illinois, Urbana-Champaign, Subcommittee Chair

- Kathryn Dewey, PhD, University of California, Davis

- Rachel Novotny, PhD, RDN, LD, University of Hawaii

- Jamie Stang, PhD, MPH, RD, University of Minnesota

- Elsie Taveras, MD, MPH, Massachusetts General Hospital, Harvard Medical School, and Harvard T.H. Chan School of Public Health

- Ronald Kleinman, MD, Massachusetts General Hospital, Harvard Medical School, Vice-Chair of the 2020 Dietary Guidelines Advisory Committee

\section{Nutrition Evidence Systematic Review (NESR) Team:}

- Ramkripa Raghavan, DrPH, MPH, MSc, Analyst, Panum Group ${ }^{\mathrm{i}}$

- Julie Nevins, PhD, Analyst, Panum Groupi

- Sara Scinto-Madonich, MS, Analyst, Panum Groupi

- Nancy Terry, MS, MLS, Biomedical Librarian, National Institutes of Health (NIH) Library, U.S. Department of Health and Human Services (HHS)

- Gisela Butera, MLIS, MEd, Systematic Review Librarian, Panum Groupi

- Julie Obbagy, PhD, RD, Project Lead, Office of Nutrition Guidance and Analysis (ONGA), Center for Nutrition Policy and Promotion (CNPP), Food and Nutrition Service (FNS), U.S. Department of Agriculture (USDA)

\section{Federal Liaisons:}

- Jean Altman, MS, ONGA, CNPP, FNS, USDA

- Meghan Adler, MS, RDN, ONGA, CNPP, FNS, USDA

- Jenna Fahle, MSPH, RDN, ONGA, CNPP, FNS, USDA (08/2019-11/2019)

\section{Project Leadership:}

- Eve Essery Stoody, PhD, Designated Federal Officer and Director, ONGA, CNPP, FNS, USDA

- Janet de Jesus, MS, RD, Nutrition Advisor, Office of Disease Prevention and Health Promotion, Office of the Assistant Secretary for Health, HHS

USDA and HHS implemented a process to identify topics and scientific questions to be examined by the 2020 Dietary Guidelines Advisory Committee. The Committee conducted its review of evidence in subcommittees for discussion by the full Committee during its public meetings. The role of the Committee members involved establishing all aspects of the protocol, which presented the plan for how they would examine the scientific evidence, including the inclusion and exclusion criteria; reviewing all studies that met the criteria they set; deliberating on the body of evidence for each question; and writing and grading the conclusion statements to be included in the scientific report the 2020 Committee submitted to USDA and HHS. The NESR

\footnotetext{
i Under contract with the Food and Nutrition Service, United States Department of Agriculture.
} 
team with assistance from Federal Liaisons and Project Leadership, supported the Committee by facilitating, executing, and documenting the work necessary to ensure the reviews were completed in accordance with NESR methodology. More information about the 2020 Dietary Guidelines Advisory Committee, including the process used to identify topics and questions, can be found at www.DietaryGuidelines.gov. More information about NESR can be found at NESR.usda.gov.

FUNDING SOURCE: United States Department of Agriculture, Food and Nutrition Service, Center for Nutrition Policy and Promotion, Alexandria, VA 


\section{TABLE OF CONTENTS}

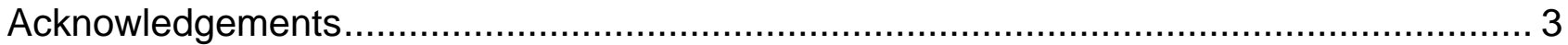

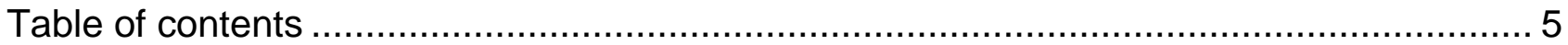

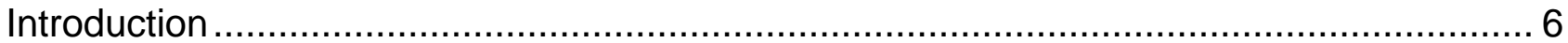

What is the relationship between dietary patterns consumed during lactation and developmental milestones, including neurocognitive development, in the child?................ 8

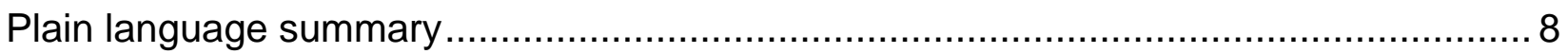

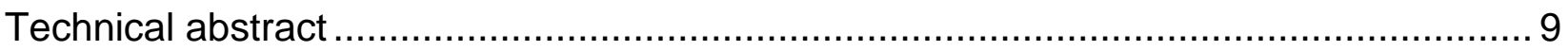

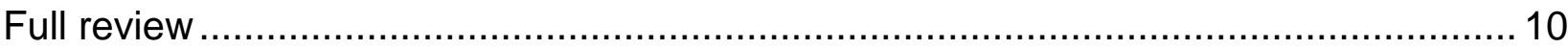

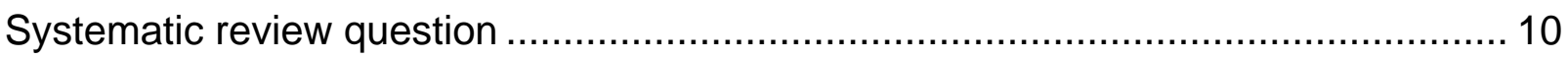

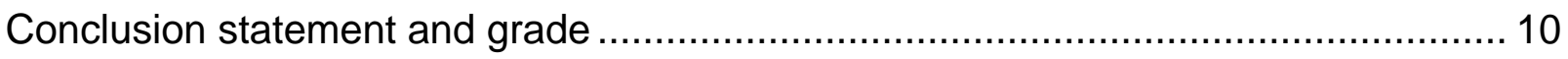

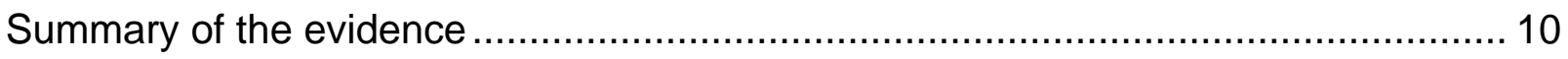

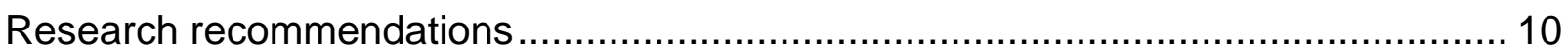

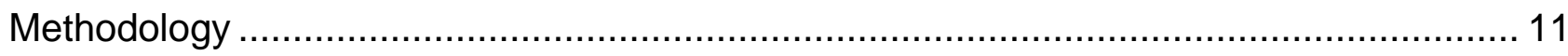

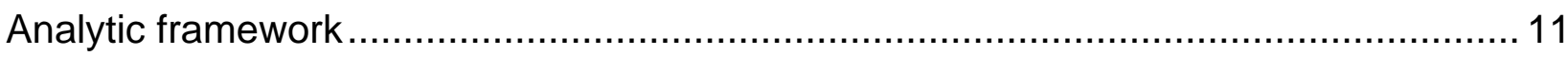

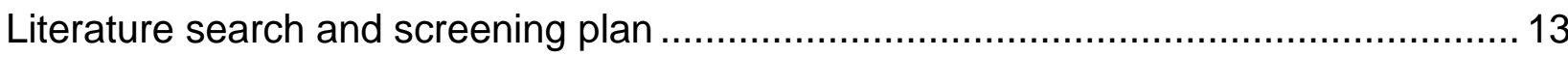

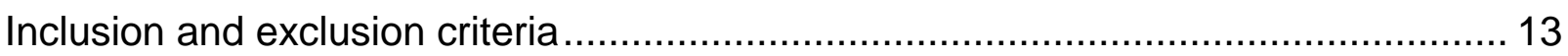

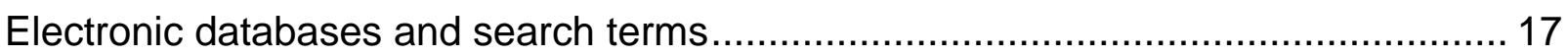

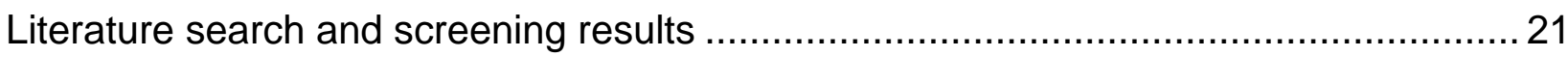

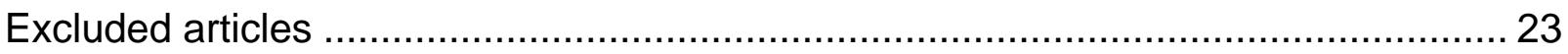

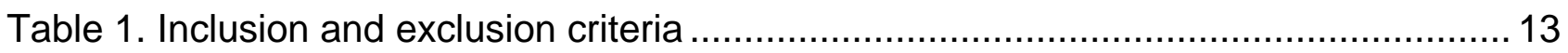

Table 2. Articles excluded after full text screening with rationale for exclusion................... 23

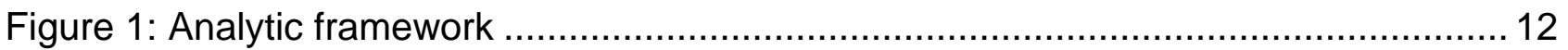

Figure 2: Flow chart of literature search and screening results.................................... 22 
This document describes a systematic review conducted to answer the following question: What is the relationship between dietary patterns consumed during lactation and developmental milestones, including neurocognitive development, in the child? This systematic review was conducted by the 2020 Dietary Guidelines Advisory Committee, supported by USDA's Nutrition Evidence Systematic Review (NESR).

More information about the 2020 Dietary Guidelines Advisory Committee is available at the following website: www.DietaryGuidelines.gov.

NESR specializes in conducting food- and nutrition-related systematic reviews using a rigorous, protocol-driven methodology. More information about NESR is available at the following website: NESR.usda.gov.

NESR's systematic review methodology involves developing a protocol, searching for and selecting studies, extracting data from and assessing the risk of bias of each included study, synthesizing the evidence, developing conclusion statements, grading the evidence underlying the conclusion statements, and recommending future research. A detailed description of the systematic reviews conducted for the 2020 Dietary Guidelines Advisory Committee, including information about methodology, is available on the NESR website: https://nesr.usda.gov/2020-dietary-guidelines-advisory-committee-systematic-reviews. In addition, starting on page 11, this document describes the final protocol as it was applied in the systematic review. A description of and rationale for modifications made to the protocol are described in the 2020 Dietary Guidelines Advisory Committee Report, Part D: Chapter 3. Food, Beverage, and Nutrient Consumption During Lactation. 


\section{List of abbreviations}

\section{Abbreviation Full name}

HHS Department of Health and Human Services

NESR Nutrition Evidence Systematic Review

USDA United States Department of Agriculture 


\section{PLAIN LANGUAGE SUMMARY}

What is the question?

- The question is: What is the relationship between dietary patterns consumed during lactation and developmental milestones, including neurocognitive development, in the child?

What is the answer to the question?

- No evidence is available to determine the relationship between maternal dietary patterns during lactation and developmental outcomes, including neurocognitive development, in the child.

Why was this question asked?

- This important public health question was identified by the U.S. Departments of Agriculture (USDA) and Health and Human Services (HHS) to be examined by the 2020 Dietary Guidelines Advisory Committee.

How was this question answered?

- The 2020 Dietary Guidelines Advisory Committee, Pregnancy and Lactation Subcommittee conducted a systematic review to answer this question with support from the Nutrition Evidence Systematic Review (NESR) team.

- Dietary patterns were defined as the quantities, proportions, variety, or combination of different foods, drinks, and nutrients (when available) in diets, and the frequency with which they are habitually consumed.

- Diets based on macronutrient distribution were examined when at least one macronutrient proportion was outside of the acceptable macronutrient distribution range (AMDR) for carbohydrate, fat, and/or protein, whether or not the foods/food groups consumed were provided.

What is the population of interest?

- For the intervention/exposure, generally healthy, lactating women.

- For the outcome, infants and toddlers (birth to 24 months) and children and adolescents (ages 2-18 years).

What evidence was found?

- This review identified 0 studies that met the inclusion criteria.

How up-to-date is this systematic review?

- This review searched for studies from January 2000 to January 2020. 


\section{TECHNICAL ABSTRACT}

\section{Background}

- This important public health question was identified by the U.S. Departments of Agriculture (USDA) and Health and Human Services (HHS) to be examined by the 2020 Dietary Guidelines Advisory Committee.

- The 2020 Dietary Guidelines Advisory Committee, Pregnancy and Lactation Subcommittee conducted a systematic review to answer this question with support from the Nutrition Evidence Systematic Review (NESR) team.

- The goal of this systematic review was to examine the following question: What is the relationship between dietary patterns consumed during lactation and developmental milestones, including neurocognitive development, in the child?

\section{Conclusion statement and grade}

- No evidence is available to determine the relationship between maternal dietary patterns during lactation and developmental outcomes, including neurocognitive development, in the child. (Grade: Grade not assignable)

\section{Methods}

- A literature search was conducted using four databases (PubMed, Cochrane, Embase, and CINAHL) to identify articles that evaluated the intervention or exposure of dietary patterns during lactation and the outcome of developmental milestones, including neurocognitive development, in the child. Articles were screened by two authors independently for inclusion based on pre-determined criteria.

- Because no articles were identified in the literature search, this systematic review did not involve data extraction, risk of bias assessment, or evidence synthesis. However, a conclusion statement was developed that acknowledged the absence of evidence to address this question. Since no evidence was available to answer this question, the strength of evidence could not be graded.

\section{Summary of the evidence}

- The outcomes for this systematic review included developmental domains (examined through milestone achievement and/or scales/indices, including cognitive, language and communication, movement and physical, and socialemotional), academic performance, attention deficit disorder or attentiondeficit/hyperactivity disorder, anxiety, depression, and autism spectrum disorder.

- This review identified 0 studies published between January 2000 and January 2020 that met the inclusion criteria for this systematic review. 


\section{FULL REVIEW}

\section{Systematic review question}

What is the relationship between dietary patterns consumed during lactation and developmental milestones, including neurocognitive development, in the child?

\section{Conclusion statement and grade}

No evidence is available to determine the relationship between maternal dietary patterns during lactation and developmental outcomes, including neurocognitive development, in the child. (Grade: Grade not assignable)

\section{Summary of the evidence}

- The outcomes for this systematic review included developmental domains (examined through milestone achievement and/or scales/indices, including cognitive, language and communication, movement and physical, and socialemotional), academic performance, attention deficit disorder or attentiondeficit/hyperactivity disorder, anxiety, depression, and autism spectrum disorder.

- This review identified 0 studies published between January 2000 and January 2020 that met the inclusion criteria for this systematic review.

\section{Research recommendations}

- More controlled trials and well-conducted observational studies that assess the relationship between maternal dietary patterns during lactation and child developmental milestones are needed.

- Future studies should use dietary patterns consistently so that they can be compared and reproduced across studies.

- Future studies should include diverse populations with varying age groups and different racial/ethnic and socioeconomic backgrounds.

- Future research should report key confounders and other factors to be considered, such as:

- Maternal age, race/ethnicity, socioeconomic status, smoking, anthropometry (obesity status during lactation, gestational weight gain), parity, child sex, gestational age at birth, human milk feeding practices (duration, exclusivity)

- Maternal substance use (alcohol, drug use), family history/diagnosis of neurocognitive disorders, complementary feeding. 
The NESR team used its rigorous, protocol-driven methodology to support the 2020 Dietary Guidelines Advisory Committee in conducting this systematic review.

NESR's systematic review methodology involves:

- Developing a protocol,

- Searching for and selecting studies,

- Extracting data from and assessing the risk of bias of each included study,

- Synthesizing the evidence,

- Developing conclusion statements,

- Grading the evidence underlying the conclusion statements, and

- Recommending future research.

A detailed description of the methodology used in conducting this systematic review is available on the NESR website: https://nesr.usda.gov/2020-dietary-guidelines-advisory-committee-systematicreviews, and can be found in the 2020 Dietary Guidelines Advisory Committee Report, Part C: Methodology. .i Additional information about this systematic review, including a description of and rationale for any modifications made to the protocol can be found in the 2020 Dietary Guidelines Advisory Committee Report, Chapter 3. Food, Beverage, and Nutrient Consumption During Lactation. Below are details of the final protocol for the systematic review described herein, including the:

- Analytic framework

- Literature search and screening plan

- Literature search and screening results

\section{ANALYTIC FRAMEWORK}

The analytic framework (Figure 1) illustrates the overall scope of the systematic review, including the population, the interventions and/or exposures, comparators, and outcomes of interest. It also includes definitions of key terms and identifies key confounders considered in the systematic review. The inclusion and exclusion criteria that follow provide additional information about how parts of the analytic framework were defined and operationalized for the review.

ii Dietary Guidelines Advisory Committee. 2020. Scientific Report of the 2020 Dietary Guidelines Advisory Committee: Advisory Report to the Secretary of Agriculture and the Secretary of Health and Human Services. U.S. Department of Agriculture, Agricultural Research Service, Washington, DC. 


\section{Figure 1: Analytic framework}

\section{Systematic review question: What is the relationship between dietary patterns consumed during lactation}

and developmental milestones, including neurocognitive development, in the child?

\begin{tabular}{|ll} 
Intervention/exposure vs & \multicolumn{1}{c}{ Comparator } \\
$\begin{array}{l}\text { Consumption of and/or } \\
\text { adherence to a dietary } \\
\text { pattern. }\end{array}$ & $\begin{array}{l}\text { Consumption of and/or } \\
\text { adherence to a different } \\
\text { dietary pattern }\end{array}$ \\
& $\begin{array}{l}\text { Different levels of } \\
\text { consumption of and/or } \\
\text { adherence to a dietary } \\
\text { pattern }\end{array}$ \\
\end{tabular}

Population: Women during lactation; healthy and/or at riskfor chronic disease

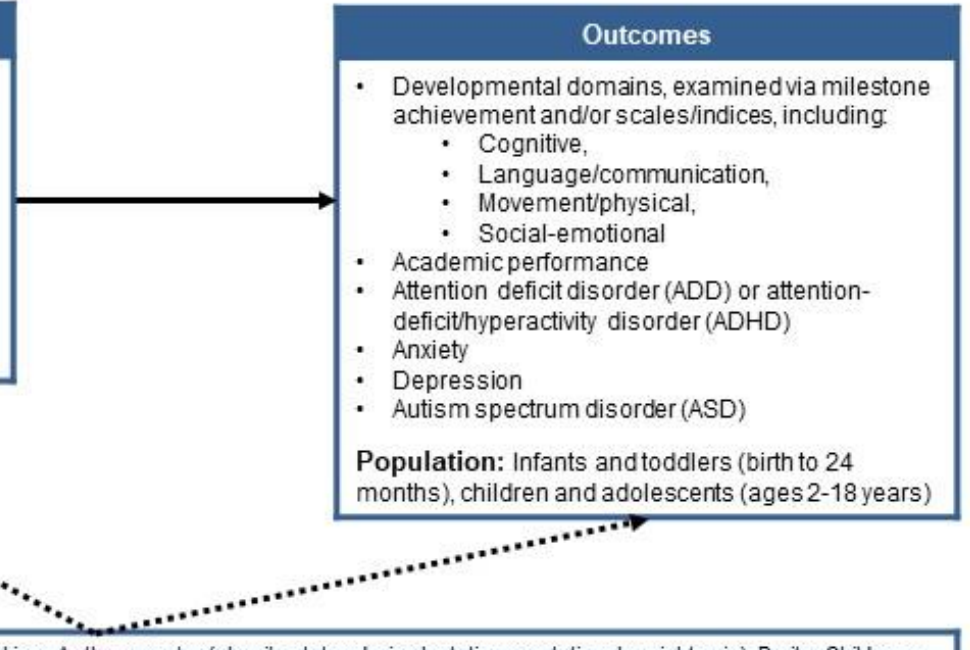

Key Confounders: Maternal age, Race/ethnicity, Socioeconomic status, Smoking, Anthropometry (obesity status during lactation, gestational weight gain), Parity, Child sex, Gestational age at birth, Human milk feeding practices (duration, exclusivity) Other factors to be considered: Maternal substance use (alcohol, drug use), Family history/diagnosis of neurocognitive disorders, complementary feeding

\section{Key definitions}

Dietary Pattern - The quantities, proportions, variety, or combination of different foods, drinks, and nutrients (when available) in diets, and the frequency with which they are habitually consumed

\section{Legend}

$\longrightarrow$ The relationship of interest in the systematic review

Factors that may impact the relationship of interest in the systematic review 


\section{LITERATURE SEARCH AND SCREENING PLAN}

\section{Inclusion and exclusion criteria}

This table provides the inclusion and exclusion criteria for the systematic review. The inclusion and exclusion criteria are a set of characteristics used to determine which articles identified in the literature search were included in or excluded from the systematic review.

\section{Table 1. Inclusion and exclusion criteria}

\begin{tabular}{|c|c|c|}
\hline Category & Inclusion Criteria & Exclusion Criteria \\
\hline $\begin{array}{l}\text { Study } \\
\text { Design }\end{array}$ & $\begin{array}{l}\text { - Randomized controlled trials } \\
\text { - Non-randomized controlled trials } \\
\text { including quasi-experimental and } \\
\text { controlled before-and-after studies } \\
\text { - Prospective cohort studies } \\
\text { - } \quad \text { Retrospective cohort studies } \\
\text { - Nested case-control studies }\end{array}$ & $\begin{array}{l}\text { - Uncontrolled trials } \\
\text { - } \text { Case-control studies } \\
\text { - } \text { Cross-sectional studies } \\
\text { - Uncontrolled before-and-after } \\
\text { studies } \\
\text { - Narrative reviews } \\
\text { - Systematic reviews } \\
\text { - } \quad \text { Meta-analyses }\end{array}$ \\
\hline \multirow[t]{4}{*}{$\begin{array}{l}\text { Intervention/ } \\
\text { exposure }\end{array}$} & $\begin{array}{l}\text { - Studies that examine consumption } \\
\text { of and/or adherence to a } \\
\text { 1. Dietary pattern [i.e., the } \\
\text { quantities, proportions, variety, } \\
\text { or combination of different } \\
\text { foods, drinks, and nutrients } \\
\text { (when available) in diets, and } \\
\text { the frequency with which they } \\
\text { are habitually consumed] } \\
\text { including, at a minimum, a } \\
\text { description of the foods and } \\
\text { beverages in the pattern }\end{array}$ & $\begin{array}{l}\text { Studies that } \\
\text { 1a. Do not provide a } \\
\text { description of the dietary } \\
\text { pattern, which at minimum, } \\
\text { must include the foods and } \\
\text { beverages in the pattern (i.e., } \\
\text { studies that examine a } \\
\text { labeled dietary pattern, but do } \\
\text { not describe the foods and } \\
\text { beverages consumed) }\end{array}$ \\
\hline & and/or & \\
\hline & $\begin{array}{l}\text { 2. Diet based on macronutrient } \\
\text { distribution outside of the } \\
\text { AMDR and } \\
\text { - Include the macronutrient } \\
\text { distribution of carbohydrate, } \\
\text { fat, and protein of the diet. }\end{array}$ & $\begin{array}{l}\text { 2a. Examine consumption of } \\
\text { and/or adherence to a diet } \\
\text { based on macronutrient } \\
\text { proportion in which all } \\
\text { macronutrients are within the } \\
\text { AMDR }\end{array}$ \\
\hline & $\begin{array}{l}\text { - Include at least one } \\
\text { macronutrient outside of the }\end{array}$ & $\begin{array}{l}\text { 2b. Do not describe the entire } \\
\text { macronutrient distribution of } \\
\text { the diet (i.e., studies that only } \\
\text { examine a single }\end{array}$ \\
\hline
\end{tabular}




\begin{tabular}{|c|c|c|}
\hline Category & Inclusion Criteria & Exclusion Criteria \\
\hline & $\begin{array}{l}\text { acceptable macronutrient } \\
\text { distribution range (AMDR }\end{array}$ & $\begin{array}{l}\text { macronutrient in relation to } \\
\text { outcomes) }\end{array}$ \\
\hline Comparator & $\begin{array}{l}\text { Dietary patterns described by foods } \\
\text { and beverages consumed: } \\
\text { - Consumption of and/or adherence } \\
\text { to a different dietary pattern } \\
\text { - Different levels of consumption of } \\
\text { and/or adherence to a dietary } \\
\text { pattern } \\
\text { Diets described by macronutrient } \\
\text { distribution: } \\
\text { - Different macronutrient distribution } \\
\text { of carbohydrate, fat, and protein }\end{array}$ & $\begin{array}{l}\text { - No comparator } \\
\text { - Macronutrient proportion(s) of } \\
\text { interest also outside the } \\
\text { AMDR }\end{array}$ \\
\hline Outcomes & $\begin{array}{l}\text { Developmental domains, } \\
\text { examined via milestone } \\
\text { achievement and/or } \\
\text { scales/indices, including: } \\
\text { o Cognitive, } \\
\text { o Language/communication, } \\
\text { o Movement/physical, } \\
\text { o Social-emotional } \\
\text { - Academic performance } \\
\text { - Attention deficit disorder (ADD) or } \\
\text { attention-deficit/hyperactivity } \\
\text { disorder (ADHD) } \\
\text { - Anxiety } \\
\text { - } \text { Depression } \\
\text { - Autism spectrum disorder (ASD) }\end{array}$ & - $\mathrm{N} / \mathrm{A}$ \\
\hline $\begin{array}{l}\text { Date of } \\
\text { publication }\end{array}$ & - January 2000 to January 2020 & $\begin{array}{l}\text { - Articles published before } \\
\text { January } 2000 \text { or after January } \\
2020\end{array}$ \\
\hline
\end{tabular}

iii Macronutrient percent of energy outside of the AMDR are as follows:

- Carbohydrate for all age groups: $<45$ or $>65$ percent of energy;

- Protein (age 19 years and older): $<10$ or $>35$ percent of energy;

- Fat (age 19 years and older): $<20$ or $>35$ percent of energy.

Institute of Medicine. Dietary Reference Intakes for Energy, Carbohydrate, Fiber, Fat, Fatty Acids, Cholesterol, Protein, and Amino Acids. Washington, DC: The National Academies Press; 2002. 


\begin{tabular}{|c|c|c|}
\hline Category & Inclusion Criteria & Exclusion Criteria \\
\hline $\begin{array}{l}\text { Publication } \\
\text { status }\end{array}$ & $\begin{array}{l}\text { - Articles that have been peer- } \\
\text { reviewed }\end{array}$ & $\begin{array}{l}\text { - Articles that have not been } \\
\text { peer-reviewed and are not } \\
\text { published in peer-reviewed } \\
\text { journals, including } \\
\text { unpublished data, } \\
\text { manuscripts, reports, } \\
\text { abstracts, and conference } \\
\text { proceedings }\end{array}$ \\
\hline $\begin{array}{l}\text { Language of } \\
\text { publication }\end{array}$ & - Articles published in English & $\begin{array}{l}\text { - Articles published in } \\
\text { languages other than English }\end{array}$ \\
\hline Countryiv & $\begin{array}{l}\text { - Studies conducted in countries } \\
\text { ranked as high or very high human } \\
\text { development }\end{array}$ & $\begin{array}{l}\text { - Studies conducted in } \\
\text { countries ranked as medium } \\
\text { or lower human development }\end{array}$ \\
\hline $\begin{array}{l}\text { Study } \\
\text { participants }\end{array}$ & - Human participants & - Animal and in vitro models \\
\hline $\begin{array}{l}\text { Life stage of } \\
\text { study } \\
\text { participants } \\
- \\
\text { intervention } \\
\text { or exposure }\end{array}$ & - Women during lactation & - $\mathrm{N} / \mathrm{A}$ \\
\hline $\begin{array}{l}\text { Life stage of } \\
\text { study } \\
\text { participants } \\
\text { - outcome: }\end{array}$ & $\begin{array}{l}\text { Infants and toddlers (birth }-24 \\
\text { months) } \\
\text { - Children and adolescents }(2-18 \\
\text { years) }\end{array}$ & $\begin{array}{l}\text { - Adults (19-64 years) } \\
\text { - Older adults (65 years and } \\
\text { older) }\end{array}$ \\
\hline $\begin{array}{l}\text { Health } \\
\text { status of } \\
\text { study } \\
\text { participants }\end{array}$ & $\begin{array}{l}\text { - Studies that enroll mothers who } \\
\text { are healthy and/or at risk for } \\
\text { chronic disease }\end{array}$ & $\begin{array}{l}\text { - Studies that exclusively } \\
\text { enroll mothers who gave } \\
\text { birth to preterm (<37 weeks) } \\
\text { - Studies that exclusively } \\
\text { enroll mothers diagnosed with }\end{array}$ \\
\hline
\end{tabular}

\footnotetext{
iv In order to determine the inclusion exclusion criteria for country, the Human Development classification was used. This classification is based on the Human Development Index (HDI) ranking from the year the study intervention occurred or data were collected (UN Development Program. HDI 1990-2017 HDRO calculations based on data from UNDESA (2017a), UNESCO Institute for Statistics (2018), United Nations Statistics Division (2018b), World Bank (2018b), Barro and Lee (2016) and IMF (2018). Available from: http://hdr.undp.org/en/data). If the study did not report the year in which the intervention occurred or data were collected, the HDI classification for the year of publication was applied. HDI values are available from 1980, and then from 1990 to present. If a study was conducted prior to 1990, the HDI classification from 1990 was applied. If a study was conducted in 2018 or 2019 , the most current HDI classification was applied. When a country was not included in the HDI ranking, the current country classification from the World Bank was used instead (The World Bank. World Bank country and lending groups. Available from: https://datahelpdesk.worldbank.org/knowledgebase/articles/906519-world- country-and-lending-groups)
} 


\begin{tabular}{|c|c|c|}
\hline Category & Inclusion Criteria & Exclusion Criteria \\
\hline & $\begin{array}{l}\text { - Studies that enroll some mothers } \\
\text { diagnosed with a disease } \\
\text { - Studies that enroll some mothers } \\
\text { who were severely undernourished } \\
\text { prior to pregnancy } \\
\text { - Studies that enroll some or all } \\
\text { mothers classified as underweight, } \\
\text { or obese prior to pregnancy }\end{array}$ & $\begin{array}{l}\text { a disease, including severe } \\
\text { undernutrition, or hospitalized } \\
\text { with an illness or injury }\end{array}$ \\
\hline Temporality & $\begin{array}{l}\text { - Studies that assess exposure prior } \\
\text { to outcome }\end{array}$ & $\begin{array}{l}\text { - Studies that assess outcome } \\
\text { prior to exposure }\end{array}$ \\
\hline
\end{tabular}




\section{Electronic databases and search terms}

\section{PubMed}

- Provider: U.S. National Library of Medicine

- Date searched: January 29, 2020

- Date range searched: January 1, 2000 - January 29, 2020

- Search terms:

\#1 - "Lactation"[Mesh] OR lactati*[tiab] OR "Breast Feeding"[Mesh] OR breastfe*[tiab] OR breast fe*[tiab] OR "Milk, Human"[Mesh] OR breastmilk[tiab] OR "breast milk"[tiab] OR "human milk"[tiab] OR "maternal milk"[tiab] OR "nursing women"[tiab]

\#2 - dietary pattern*[tiab] OR diet pattern*[tiab] OR eating pattern*[tiab] OR food pattern*[tiab] OR "diet quality"[tiab] OR eating habit*[tiab] OR dietary habit*[tiab] OR diet habit* ${ }^{\star}[$ tiab] OR food habit*[tiab] OR "Feeding Behavior"[Mesh] OR feeding behavior*[tiab] OR beverage consumption[tiab] OR beverage habit*[tiab] OR beverage intake* $[$ tiab] OR dietary profile*[tiab] OR food profile[tiab] OR diet profile*[tiab] OR eating profile*[tiab] OR dietary guideline*[tiab] OR dietary recommendation*[tiab] OR dietary intake*[tiab] OR food intake*[tiab] OR food consumption[tiab] OR dietary consumption[tiab] OR eating frequenc ${ }^{\star}[$ tiab] OR food frequenc ${ }^{\star}[$ tiab] OR eating style*[tiab] OR dietary change*[tiab] OR dietary choice*[tiab] OR food choice*[tiab] OR "Diet, Mediterranean"[Mesh] OR Mediterranean Diet"[tiab] OR "Dietary Approaches To Stop Hypertension"[Mesh] OR Dietary Approaches To Stop Hypertension Diet $^{*}\left[\right.$ tiab] OR DASH $\operatorname{diet}^{*}[$ tiab] OR "Diet, Gluten-Free"[Mesh] OR Gluten Free diet*[tiab] OR prudent diet* OR "Diet, Paleolithic"[Mesh] OR Paleolithic Diet* OR "Diet, Vegetarian"[Mesh] OR vegetarian diet*[tiab] OR vegan $\operatorname{diet}^{\star}[$ tiab] OR "Healthy Diet"[Mesh] OR plant based $\operatorname{diet}^{*}\left[\right.$ tiab] OR "Diet, Western"[Mesh] OR western $\operatorname{diet}^{*}[$ tiab] OR "Diet, CarbohydrateRestricted"[Mesh] OR low-carbohydrate $\operatorname{diet}^{*}\left[\right.$ tiab] OR high carbohydrate $\operatorname{diet}^{\star}[$ tiab] OR Ketogenic Diet*[tiab] OR Nordic Diet*[tiab] OR "Diet, Fat-Restricted"[Mesh] OR "Diet, HighFat"[Mesh] OR "Diet, High-Protein"[Mesh] OR high protein diet $^{\star}\left[\right.$ tiab] OR high-fat diet ${ }^{\star}$ [tiab] OR low fat diet*[tiab] OR "Diet, Protein-Restricted"[Mesh] OR low protein diet*[tiab] OR "Diet, Sodium-Restricted"[Mesh] OR low-sodium diet*[tiab] OR low salt diet*[tiab] OR (("Dietary Proteins"[Mesh] OR dietary protein*[tiab] OR "Dietary Carbohydrates"[Mesh] OR dietary carbohydrate*[tiab] OR "Dietary Fats"[Mesh] OR dietary fat*[tiab] OR hypocaloric[tiab] OR hypo-caloric[tiab]) AND (diet[tiab] OR diets[tiab] OR consumption[tiab] OR intake[tiab] OR supplement*[tiab])) OR ("Guideline Adherence"[Mesh] AND (diet[tiab] OR dietary[tiab] OR food[tiab] OR beverage[tiab])) OR (diet score* OR diet quality score* OR diet quality index OR dietary habits score* OR kidmed[tiab] OR diet index*[tiab] OR dietary index*[tiab] OR Food-based Index*[tiab] OR diet quality index* OR food index $x^{*}[$ tiab] OR food score*[tiab] OR Mediterranean diet score*[tiab] OR MedDietScore[tiab] OR healthy eating index[tiab] OR food frequency questionnaire*[tiab] OR food frequency survey*[tiab] OR "Nutrition Surveys"[Mesh] OR nutrition survey*[tiab] OR diet survey*[tiab] OR food survey*[tiab] OR dietary questionnaire[tiab]) OR ((pattern[tiab] OR patterns[tiab] OR consumption[tiab] OR habit*[tiab]) AND ("Diet"[Mesh:NoExp] OR diet[tiab] OR diets[tiab] OR dietary[tiab] OR "Food"[Mesh] OR food $^{*}[$ tiab] OR foods[tiab] OR "Beverages"[Mesh] OR beverage*[tiab]))

\#3 - "Mental Disorders"[Mesh] OR mental disorder*[tiab] OR Neuropsychological Tests[MeSH] OR cogniti*[tiab] OR metacogniti*[tiab] OR neurocogniti*[tiab] OR neurodevelop*[tiab] OR neurological[tiab] OR "Depression"[Mesh] OR depress*[tiab] OR anxiety[tiab] OR anxiou*[tiab] OR "Psychomotor Performance"[Mesh] OR psychomotor[tiab] OR motor skill*[tiab] OR executive function*[tiab] OR attention deficit*[tiab] OR ADHD[tiab] OR behavior disorder*[tiab] 
OR behavior disorder*[tiab] OR behavioral disorder*[tiab] OR developmental disorder*[tiab] OR autis*[tiab] OR asperger*[tiab] OR language processing[tiab] OR language delay*[tiab] OR Language Development[Mesh] OR developmental delay*[tiab] OR developmental disabilit*[tiab] OR problem solv*[tiab] OR developmental domain*[tiab] OR academic[tiab] OR academic performance[mh] OR mental processes[Mesh]

\#4 - \#1 AND \#2 AND \#3

\#5 - \#4 NOT ("Animals"[Mesh] NOT ("Animals"[Mesh] AND "Humans"[Mesh])) NOT (editorial[ptyp] OR comment[ptyp] OR news[ptyp] OR letter[ptyp] OR review[ptyp] OR systematic review[ptyp] OR systematic review[ti] OR meta-analysis[ptyp] OR meta-analysis[ti] OR meta-analyses[ti] OR retracted publication[ptyp] OR retraction of publication[ptyp] OR retraction of publication[tiab] OR retraction notice[ti])

Filters: Publication date from 2000/01/01 to 2020/01/29; English

\section{Cochrane Central Register of Controlled Trials (CENTRAL)}

- Provider: John Wiley \& Sons

- Date searched: January 29, 2020

- Date range searched: January 1, 2000 - January 29, 2020

- Search terms:

\#1 - [mh Lactation] OR [mh "Breast Feeding"] OR [mh "Milk, Human"] OR lact* OR breastfeeding OR breast-feeding OR breast feed ${ }^{*}$ OR breast-feed ${ }^{*}$ OR breastfed OR breastfed OR breastfeed OR "human milk" OR "nursing women"

\#2 - "dietary pattern*" OR "diet pattern*" OR "eating pattern*" OR "food pattern*" OR "diet quality" OR "eating habit"" OR "dietary habit" OR "diet habit" OR "food habit" OR [mh "Feeding Behavior"] OR "feeding behavior" OR "beverage consumption" OR "beverage habit" OR "beverage intake*" OR "dietary profile*" OR "food profile" OR "diet profile*" OR "eating profile*" OR "dietary guideline*" OR "dietary recommendation*" OR "dietary intake" OR "food intake" OR "food consumption" OR "dietary consumption" OR "eating frequenc" OR "food frequenc*" OR "eating style*" OR "dietary change*" OR "dietary choice*" OR "food choice*" OR [mh "Diet, Mediterranean"] OR "Mediterranean Diet" OR [mh "Dietary Approaches To Stop Hypertension"] OR "Dietary Approaches To Stop Hypertension Diet*" OR "DASH diet"" OR [mh "Diet, Gluten-Free"] OR "Gluten Free diet"" OR "prudent diet" OR [mh "Diet, Paleolithic"] OR "Paleolithic Diet*" OR [mh "Diet, Vegetarian"] OR "vegetarian diet*" OR "vegan diet" OR [mh "Healthy Diet"] OR "plant based diet*" OR [mh "Diet, Western"] OR "western diet*" OR [mh "Diet, Carbohydrate-Restricted"] OR "low-carbohydrate diet*" OR "high carbohydrate diet*" OR "Ketogenic Diet" OR "Nordic Diet" Restricted"] OR [mh "Diet, High-Fat"] OR [mh "Diet, High-Protein"] OR "high protein diet"" OR "high-fat diet*" OR "low fat diet" OR [mh "Diet, Protein-Restricted"] OR "low protein diet" OR [mh "Diet, Sodium-Restricted"] OR "low-sodium diet" OR "low salt diet*"OR (([mh "Dietary Proteins"] OR "dietary protein*" OR [mh "Dietary Carbohydrates"] OR "dietary carbohydrate" OR [mh "Dietary Fats"] OR "dietary fat*" OR hypocaloric OR hypo-caloric) NEAR (diet OR diets OR consumption OR intake OR supplement*)) OR ("guideline adherence") NEAR/4 (diet OR dietary OR food OR beverage)) OR ("diet score" OR "diet scores" OR "diet quality score" OR "diet quality scores" OR "diet quality index" OR "dietary habits score" OR kidmed OR "diet index" OR "dietary index" OR "Food-based Index" OR "diet quality index" OR "food index" OR "food score" OR "food scores" OR "Mediterranean diet score" OR MedDietScore OR "healthy 
eating index" OR "food frequency questionnaire" OR "food frequency questionnaires" OR "food frequency survey" OR "food frequency surveys" OR [mh "Nutrition Surveys"] OR "nutrition survey" OR "nutrition surveys" OR "diet survey" OR "diet surveys" OR "food survey" OR "food surveys" OR "dietary questionnaire"):ti,ab,kw OR ((pattern OR patterns OR consumption OR habit ${ }^{\star}$ ) NEAR ([mh ^ ${ }^{\wedge}$ iet] OR diet OR diets OR dietary OR [mh Food] OR food OR foods OR [mh Beverages] OR beverage OR beverages)):ti,ab,kw

\#3 - ([mh "Mental Disorders"] OR [mh "Cognition"] OR [mh "Cognitive Dysfunction"] OR [mh "Depressive Disorder"] OR [mh "Depression"] OR [mh "Psychomotor Performance"] OR [mh "Executive Function"] OR [mh "Attention Deficit and Disruptive Behavior Disorders"] OR [mh "Child Behavior Disorders"] OR [mh "Autism Spectrum Disorder"] OR [mh "Developmental Disabilities"] OR [mh "Motor Skills Disorders"] OR [mh "Problem Solving"] OR "mental disorder*" OR cognition OR cognitive OR metacognition OR neurocognitive OR neurodevelop* OR depression OR anxiety OR "motor skill" OR "executive function*" OR "attention deficit disorder" OR ADHD OR "developmental disorder" OR autism OR autistic OR Asperger* OR "language processing" OR "language delay" OR "child develop*" OR "developmental delay" OR "developmental disabilit*" OR "motor skill*" OR "developmental domain*" OR "academic performance" OR [mh "academic performance"] OR "academic achievement" OR "academic failure" OR "academic success"):ti,ab,kw

\#4 - \#1 AND \#2 AND \#3

Filters: Publication Year from 2000 - 2020, Trials

\section{Embase}

- Provider: Elsevier

- Date searched: January 29, 2020

- Date range searched: January 1, 2000 - January 29, 2020

- Search terms:

\#1 - Lact*:ab,ti OR breastfeeding:ab,ti OR breast-feeding:ab,ti OR 'breast feed"':ab,ti OR breastfed:ab,ti OR 'breast fed':ab,ti OR breastfeed:ab,ti OR 'human milk':ab,ti OR 'nursing women':ab,ti OR 'lactation'/mj OR 'breast feeding'/exp/mj OR 'breast milk'/exp/mj

\#2 - 'feeding behavior'/exp OR 'mediterranean diet'/de OR 'dash diet'/de OR 'gluten free diet'/exp OR 'paleolithic diet'/de OR 'vegetarian diet'/exp OR 'healthy diet'/de OR 'western diet'/de OR 'low carbohydrate diet'/exp OR 'low fat diet'/de OR 'lipid diet'/exp OR 'protein diet'/exp OR 'protein restriction'/de OR 'sodium restriction'/de OR 'dietary pattern*':ab,ti OR 'diet pattern*':ab,ti OR 'eating pattern*':ab,ti OR 'food pattern':ab,ti OR 'diet quality':ab,ti OR 'eating habit': ab,ti OR 'dietary habit': ab,ti OR 'diet habit"':ab,ti OR 'food habit"':ab,ti OR 'feeding behavior"':ab,ti OR 'beverage consumption':ab,ti OR 'beverage habit': ab,ti OR 'beverage intake ${ }^{\star \prime}: a b, t i$ OR 'dietary profile ${ }^{\star \prime}: a b, t i$ OR 'food profile':ab,ti OR 'diet profile*':ab,ti OR 'eating profile*':ab,ti OR 'dietary guideline ${ }^{* \prime}: a b, t i$ OR 'dietary recommendation':ab,ti OR 'dietary intake':ab,ti OR 'food intake':ab,ti OR 'food consumption':ab,ti OR 'dietary consumption':ab,ti OR 'eating frequenc ${ }^{\star \prime}: a b, t i$ OR 'food frequenc ${ }^{\star \prime}: a b$, ti OR 'eating style ${ }^{\star \prime}: a b, t i$ OR 'dietary change ${ }^{* \prime}: a b, t i$ OR 'dietary choice ${ }^{* \prime}: a b, t i$ OR 'food choice*':ab,ti OR 'mediterranean $\operatorname{diet}^{\star \prime}: a b, t i$ OR 'dietary approaches to stop hypertension diet $^{\star \prime}: a b, t i$ OR 'dash diet $^{\star \prime}: a b, t i$ OR

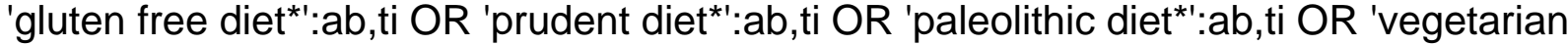
$\operatorname{diet}^{\star \prime}:$ ab,ti OR 'vegan $\operatorname{diet}^{\star \prime}: a b$, ti OR 'plant based diet $^{\star \prime}: a b$, ti OR 'western $\operatorname{diet}^{\star \prime}:$ ab,ti OR 'lowcarbohydrate diet ${ }^{* \prime}: a b, t i$ OR 'high carbohydrate diet $^{* \prime}: a b, t i$ OR 'ketogenic diet ${ }^{* \prime}: a b, t i$ OR 'nordic 
diet $^{\star \prime}:$ ab,ti OR 'high protein diet $^{\star \prime}: a b, t i$ OR 'high-fat diet ${ }^{\star \prime}: a b, t i$ OR 'low fat diet ${ }^{\star \prime}: a b, t i$ OR 'low

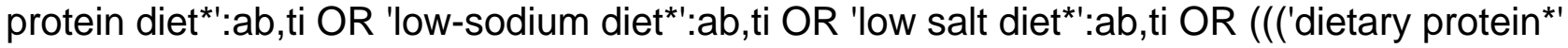
OR 'dietary carbohydrate*' OR 'dietary fat*' OR hypocaloric OR 'hypo caloric') NEAR/6 (diet OR diets OR consumption OR intake OR supplement*)):ab,ti) OR (('guideline adherence' NEAR/6 (diet OR dietary OR food OR beverage)):ab,ti) OR 'diet score ${ }^{\star \prime}: a b, t i$ OR 'diet quality score $^{* 1}: a b, t i$ OR 'dietary habits score*':ab,ti OR kidmed:ab,ti OR 'diet index*':ab,ti OR 'dietary index ${ }^{* \prime}: a b$, ti OR 'food-based index*':ab,ti OR 'diet quality index':ab,ti OR 'food index"':ab,ti OR 'food score*':ab,ti OR 'mediterranean diet score*':ab,ti OR meddietscore:ab,ti OR 'healthy eating index':ab,ti OR 'food frequency questionnaire ${ }^{* \prime}: a b, t i$ OR 'food frequency survey ${ }^{\star \prime}: a b, t i$ OR 'nutrition survey*':ab,ti OR 'diet survey*':ab,ti OR 'food survey': ab,ti OR 'dietary questionnaire':ab,ti OR (((pattern OR patterns OR consumption OR habit*) NEAR/6 (diet OR diets OR dietary OR food OR foods OR beverage OR beverages)):ab,ti)

\#3 - 'mental disease'/exp OR 'cognition'/exp OR 'cognitive defect'/exp OR 'depression'/exp OR 'psychomotor performance'/de OR 'executive function'/de OR 'attention deficit disorder'/de OR 'autism'/exp OR 'child development'/de OR 'developmental disorder'/exp OR 'psychomotor disorder'/de OR 'problem solving'/de OR 'academic performance'/exp OR 'mental disorder':ab,ti OR cognition:ab,ti OR cognitive:ab,ti OR metacognition:ab,ti OR neurocognitive:ab,ti OR neurodevelop*:ab,ti OR neurological:ab,ti OR depression:ab,ti OR anxiety:ab,ti OR 'executive function ': $a b, t i$ OR 'attention deficit disorder*':ab,ti OR adhd:ab,ti OR 'developmental disorder':ab,ti OR autism:ab,ti OR asperger:ab,ti OR 'language processing':ab,ti OR 'language delay':ab,ti OR 'developmental delay':ab,ti OR 'developmental disabilit"':ab,ti OR 'motor skill' :ab,ti OR 'developmental domain*':ab,ti OR 'academic performance':ab,ti OR 'academic achievement':ab,ti OR 'academic failure':ab,ti OR 'academic success $^{\star \prime}: a b$, ti

\#4 - \#1 AND \#2 AND \#3

\#5 - \#4 AND ([article]/lim OR [article in press]/lim) AND [humans]/lim AND [english]/lim AND [2000-2020]/py NOT ([conference abstract]/lim OR [conference paper]/lim OR [editorial]/lim OR [erratum]/lim OR [letter]/lim OR [note]/lim OR [review]/lim OR [systematic review]/lim OR [meta analysis]/lim)

\section{Cumulative Index of Nursing and Allied Health Literature (CINAHL Plus)}

- Provider: EBSCOhost

- Date searched: January 29, 2020

- Date range searched: January 1, 2000 - January 29, 2020

- Search terms:

\#1 - MH "Breast Feeding" OR breastfeeding OR breast-feeding OR MH "Milk, Human" OR "human milk" OR MH Lactation OR lactation OR lactating OR breastfeeding OR "breast feed" OR breast-feed ${ }^{*}$ OR breastfed OR breast-fed OR breastfeed ${ }^{*}$ OR "nursing women" OR "nursing mother"

\#2 - "dietary pattern*" OR "diet pattern*" OR "eating pattern*" OR "food pattern*" OR "diet quality" OR "eating habit" OR "dietary habit"” OR "diet habit"” OR "food habit*" OR MH "Eating Behavior+" OR "feeding behavior" OR "beverage consumption" OR "beverage habit" OR "beverage intake*" OR "dietary profile*" OR "food profile*" OR "diet profile*" OR "eating profile" OR "dietary guideline *" OR "dietary recommendation*" OR "dietary intake*" OR "food intake" OR "food consumption" OR "dietary consumption" OR "eating frequenc" OR "food 
frequenc*" OR "eating style*" OR "dietary change*" OR "dietary choice*" OR "food choice*" OR MH "Diet, Mediterranean" OR "Mediterranean Diet" OR MH "Dietary Approaches To Stop Hypertension" OR "Dietary Approaches To Stop Hypertension Diet*" OR "DASH diet" OR MH "Diet, Gluten-Free" OR "Gluten Free diet*" OR "prudent diet"” OR MH "Diet, Paleolithic" OR "Paleolithic Diet" OR MH "Diet, Vegetarian" OR "vegetarian diet" OR "vegan

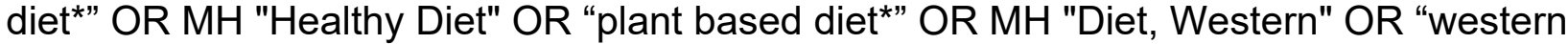
diet"” OR MH "Diet, Carbohydrate-Restricted" OR "low-carbohydrate diet"” OR "high carbohydrate diet"” OR "Ketogenic Diet*" OR "Nordic Diet"” OR MH "Diet, Fat-Restricted" OR MH "Diet, High-Fat" OR MH "Diet, High-Protein" OR "high protein diet" OR "high-fat diet" OR "low fat diet"” OR MH "Diet, Protein-Restricted" OR "low protein diet"” OR MH "Diet, Sodium-Restricted" OR "low-sodium diet"” OR "low salt diet*" OR ((MH "Dietary Proteins" OR "dietary protein*" OR MH "Dietary Carbohydrates" OR "dietary carbohydrate*" OR MH "Dietary Fats" OR "dietary fat"” OR hypocaloric OR hypo-caloric) AND (diet OR diets OR consumption OR intake OR supplementation)) OR (MH "Guideline Adherence" AND (diet OR dietary OR food OR beverage)) OR ("diet score*" OR "diet quality score*" OR "diet quality index" OR "dietary habits score*" OR kidmed OR "diet index" OR "dietary index" OR "Food-based Index"” OR "diet quality index" OR "food index" OR "food score*" OR "Mediterranean diet score*" OR MedDietScore OR "healthy eating index" OR "food frequency questionnaire*" OR "food frequency survey*" OR MH "Nutrition Surveys" OR "nutrition survey" OR "diet survey*" OR "food survey" OR "dietary questionnaire*") OR ((pattern OR patterns OR consumption OR habit") AND (MH "Diet" OR diet OR diets OR dietary OR MH "Food" OR food OR foods OR MH "Beverages" OR beverage OR beverages))

\#3 - (MH "Mental Disorders+") OR "mental disorder" OR (MH "Cognition+") OR cognition OR cognitive OR metacognition OR neurocognitive OR neurodevelop* OR neurological OR "cognitive dysfunction" OR "depressive disorders OR (MH "Depression") OR depression OR (MH "Anxiety") OR anxiety OR (MH "Psychomotor Performance") OR motor skill* OR (MH "Executive Function") OR executive function* OR (MH "Attention Deficit Hyperactivity Disorder") OR attention deficit disorder* OR ADHD OR (MH "Child Behavior Disorders") OR developmental disorder* OR (MH "Autistic Disorder") OR autism OR Asperger OR "language processing" OR language delay* OR (MH "Developmental Disabilities") OR developmental delay $^{*}$ OR developmental disabilit* OR (MH "Motor Skills Disorders") OR motor skill* OR (MH "Problem Solving") OR developmental domain* OR (MH "academic performance") OR "academic performance" OR "academic achievement" OR "academic failure" OR academic success*

\#4 - \#1 AND \#2 AND \#3

\#5 - \#4 NOT (MH "Literature Review" OR MH "Meta Analysis" OR MH "Systematic Review" OR MH "News" OR MH "Retracted Publication" OR MH "Retraction of Publication )

Filters: Published Date: 20000101-20200129, English Language; Human

\section{LITERATURE SEARCH AND SCREENING RESULTS}

The flow chart (Figure 2) below illustrates the literature search and screening results for articles examining the systematic review question. The results of the electronic database searches, after removal of duplicates, were screened independently by two NESR analysts using a step-wise process by reviewing titles, abstracts, and full-texts to determine which 
articles met the inclusion criteria. Refer to Table 2 for the rationale for exclusion for each excluded full-text article. A manual search was done to find articles that were not identified when searching the electronic databases; all manually identified articles are also screened to determine whether they meet criteria for inclusion.

\section{Figure 2: Flow chart of literature search and screening results}

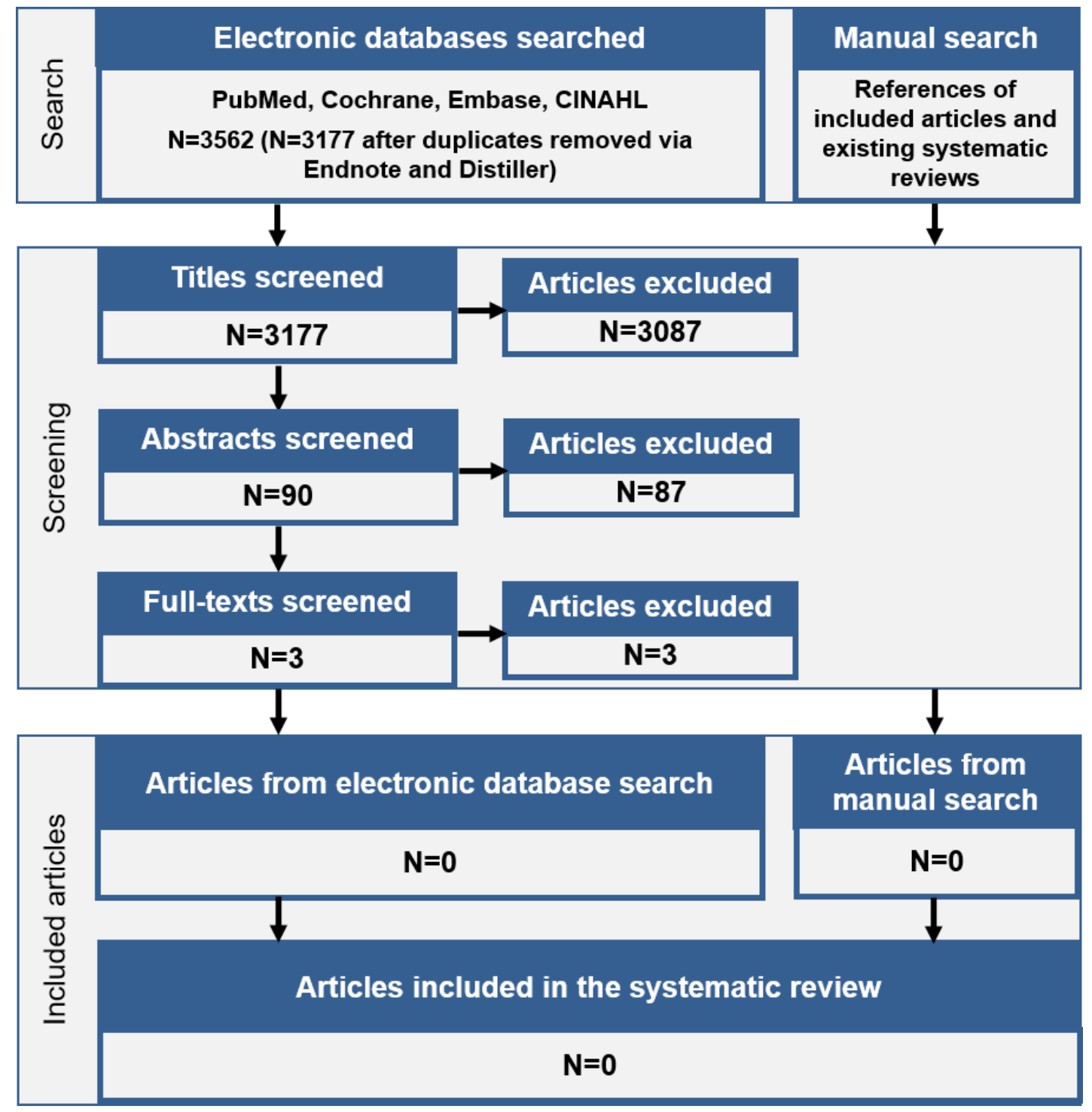




\section{Excluded articles}

The table below lists the articles excluded after full-text screening, and includes rationale for the categories of inclusion and exclusion criteria (see Table 1) that studies were excluded based on. At least one reason for exclusion is provided for each article, though this may not reflect all possible reasons for exclusion. Information about articles excluded after title and abstract screening is available upon request.

\section{Table 2. Articles excluded after full text screening with rationale for exclusion}

\begin{tabular}{cllc}
\hline Citation & Rationale \\
\hline 1. & $\begin{array}{l}\text { Crozier, SR, Godfrey, KM, Calder, PC, Robinson, SM, Inskip, HM, Baird, J, Gale, CR, Cooper, C, Sibbons, } \\
\text { CM, Fisk, HL, Burdge, GC. Vegetarian Diet during Pregnancy Is Not Associated with Poorer Cognitive } \\
\text { Performance in Children at Age 6-7 Years. Nutrients. 2019. 11. doi:10.3390/nu11123029. }\end{array}$ & Intervention/Exposure; Population \\
& $\begin{array}{l}\text { Krzeczkowski, JE, Boylan, K, Arbuckle, TE, Muckle, G, Poliakova, N, Seguin, JR, Favotto, LA, Savoy, C, } \\
\text { Amani, B, Mortaji, N, Van Lieshout, RJ. Maternal Pregnancy Diet Quality Is Directly Associated with } \\
\text { Autonomic Nervous System Function in 6-Month-Old Offspring. J Nutr. 2019. doi:10.1093/jn/nxz228. }\end{array}$ & Population; Outcome \\
\hline 3. & $\begin{array}{l}\text { Marques, RC, Garrofe Dorea, J, Rodrigues Bastos, W, de Freitas Rebelo, M, de Freitas Fonseca, M, Malm, } \\
\text { O. Maternal mercury exposure and neuro-motor development in breastfed infants from Porto Velho } \\
\text { (Amazon), Brazil. Int J Hyg Environ Health. 2007. 210:51-60. doi:10.1016/j.ijheh.2006.08.001. }\end{array}$ & Intervention/Exposure \\
\hline
\end{tabular}

